\title{
Hunger and Malnutrition in India
}

\author{
N.C. Saxena
}

Abstract Despite excellent economic growth in the last two decades India continues to suffer from 'alarming'
hunger, and acute malnutrition amongst children under five. The recently introduced National Food Security
Bill tries to address some of these concerns, but its success would depend on several non-legal factors, such as
whether we are able to increase food production in backward regions, ban exports and thus increase availability,
and identify the real poor correctly with some help from the biometrics-based unique identity (UID) programme.
The Government of India also has to improve the design and oversight of central welfare programmes such as
the Public Distribution System (PDS), which seeks to distribute subsidised foodgrains to the poor, and the
Integrated Child Development Services (ICDS) meant for children under five. However, food alone does not
solve the problem of underweight children, which needs a multidimensional thrust in health, hygiene, water
quality, and above all a change in cultural practices related to child-rearing.

India's excellent economic growth has had little impact on its social indicators, and unless urgent ameliorative steps are taken India is likely to miss achieving the Millennium Development Goals in respect of hunger, poverty reduction, health, nutrition, sanitation and gender. Two recent reports confirm this. According to the 2011 Global Hunger Index Report (IFPRI), India continues to be in the category of those nations where hunger is 'alarming'. What is worse, India is one of the three unfortunate countries where the hunger index between 1996 and 2011 has gone up from 22.9 to 23.7, while 78 out of the 81 developing countries studied, including Pakistan, Nepal, Bangladesh, Vietnam, Kenya, Nigeria, Myanmar, Uganda, Zimbabwe and Malawi, have all succeeded in reducing hunger. Second, the 2011 hunger and malnutrition (popularly known as HUNGaMA) report released by the Prime Minister in January 2012, shows that the number of malnourished children in the 100 districts continues to be above 40 per cent.

Would the National Food Security Bill (NFSB) recently introduced in Parliament be able to reduce hunger and malnutrition in India? The answer depends on several non-legal factors, such as whether we are able to increase food production in backward regions, ban exports and thus increase availability, and identify the real poor correctly. The Government of India (GoI) also has to improve the design of central programmes such as Public Distribution System (PDS) and

Integrated Child Development Services (ICDS) and improve its monitoring of them. However, as argued later in this article, food alone does not solve the problem of underweight children, which needs a multidimensional thrust in health, hygiene, quality of water and, above all, a change in cultural practices related to child-rearing.

We discuss food security first.

According to the Economic Survey 2011, foodgrain production in India has dropped from $208 \mathrm{~kg}$ per annum per capita in 1996-97 to $186 \mathrm{~kg}$ in 2009-10, a decline of 11 per cent. Despite reduced production, India has been exporting an average 7 million tonnes of cereals per annum, causing availability to decline further by 15 per cent. This has adversely affected the cereal intake of the bottom 20 per cent of the population which continues to be at least 20 per cent less than the cereal intake of the top decile of the population, despite the rich doing less manual work and having better access to fruits, vegetables and meat products. Those who are around the poverty line, notwithstanding marginal increases in their incomes over time, are forced to cut down on their food consumption to meet other pressing demands of health and education that were not considered important in the past. Food is still needed, but not demanded for lack of money. Endemic hunger thus 
continues to afflict a large proportion of the Indian population.

\section{Focus on small farms and backward regions}

Food insecurity and hunger are caused by a large number of factors and hence solutions too have to be multisectoral in nature. First, revamp smallholder agriculture. Because of stagnating growth in agriculture after the mid-1990s there has been employment decline, income decline and hence a fall in aggregate demand from the rural poor. The most important intervention that is needed is greater investment in irrigation, power, agricultural research and development, and roads in the poorer regions of central and eastern India, where the concentration of poverty is increasing.

The stated objective of the ambitious MGNREGS (Mahatma Gandhi National Rural Employment Guarantee Scheme) is to do drought-proofing and increase agricultural production on marginal holdings, especially in semi-arid regions and uplands, but the sustainability and productivity of assets created is never monitored, with the result that the programme is reduced to creating shortterm unproductive employment with no focus on asset creation or soil and water conservation (Hirway 2011). Its impact on agriculture may even be negative, as alleged by the Ministry of Agriculture (Indian Express 2011). In any case it makes no sense to run the programme in the labour-scarce districts of Kerala, Punjab, Haryana, Himachal Pradesh, and the North-East. On the other hand, the upper limit of work guarantee of 100 days should be enhanced to 150 days per household in the poorest 200 districts, with assets such as ponds, bunds, check dams, and planted saplings being monitored for at least five years.

\section{The National Food Security Bill (NFSB)}

On the positive side, NFSB will increase the below poverty line (BPL) coverage of those getting subsidised foodgrains from the present level of 65 million households to 100 million priority households. They will have to pay only Rs 2-3 per kilo for wheat and rice as against approximately Rs 6 that they pay right now. In addition, another 80 million households will be covered under the general category. Thus 180 out of the present population of 240 million households will get subsidised rations. We need about 50 million tonnes of grain annually to meet this demand, as against annual procurement of 60-65 million tonnes in the last three years, thus leaving sufficient quantity for other welfare programmes like midday meals. It is hoped that the government will also push up the direct purchase of paddy in states like Bihar, Uttar Pradesh (UP), and Madhya Pradesh(MP) where the paddy farmers are largely dependent on rice millers who pay a pittance, thus depriving farmers in these states the benefit of the minimum support price that Haryana and Punjab farmers enjoy.

The proposed Act will be enforced largely through the Targeted Public Distribution System, which unfortunately suffers from severe systemic flaws. The Planning Commission survey (2004) says that 58 per cent of the subsidised foodgrains do not reach the BPL families, with 36 per cent on the black market, and the rest reaching the non-poor. Diversion of commodities is a big problem due to lack of transparency, low accountability and poor monitoring in the scheme's implementation. Central government cannot close its eyes to largescale fraud in PDS by taking the narrow 'constitutional' position that implementation is the state's responsibility. The Food Ministry should have a greater sense of ownership of the scheme, and improve its oversight mechanisms. For instance, it should start an annual impact study of the PDS, especially in the poorer states.

In addition, one should launch a drive in collaboration with civil society to cover the poorest, as a large number of people in remote tribal villages, the homeless or those living in unauthorised colonies in urban areas have been denied ration cards, and are thus not able to benefit from the PDS, on the grounds that they do not have an address! In Rangpur Pahadi, a slum area just $4 \mathrm{~km}$ away from Vasant Kunj (Delhi), people living there since 1990 have not been given even voter ID or any ration card (the author himself visited the slum in 2010). Thus their very existence is denied by the Delhi Government!

Fortunately many states have tried to improve the PDS. It had always worked quite well in Tamil Nadu, Kerala, Himachal Pradesh and Andhra Pradesh, but now states like Chhattisgarh, Orissa and Rajasthan (Khera 2011) have undertaken state-level PDS reforms by extending coverage, improving delivery and increasing transparency. The best results are seen in Chhattisgarh (see Box 1) because of replacement of private dealers 


\section{Box 1 Public Distribution System in Chhattisgarh}

A survey of PDS in two districts of Chhattisgarh revealed that 88 per cent of the respondents were satisfied with the functioning of their ration shops and were getting their foodgrains regularly at the correct prices. Government has shifted the management of ration shops from private dealers to community-based organisations such as gram panchayats, self-help groups (SHGs) and cooperatives. To reduce leakages, the government decided to dispense with private players and directly deliver foodgrains to ration shops in government trucks painted yellow. Transition from a targeted to a 'quasi-universal' PDS, one that covers approximately 80 per cent of the state's rural population, not only helped in improving the functioning of the PDS by giving a majority of the people in villages a stake in their local ration shop, but also reduced exclusion errors that occurred due to the faulty targeting system used by the Central Government. The other steps are: increasing the commission paid to ration shopkeepers from Rs 8 to Rs 30 per quintal of rice; procuring more foodgrains from farmers in the state to encourage them to raise outputs; making electronic weighing scales mandatory in all ration shops; and conducting verification drives to identify and cancel bogus ration cards.

Source Puri (2012).

by panchayats, increased commissions, coverage of more than 80 per cent of families under the scheme as opposed to only 40 per cent who are officially recognised as BPL by GoI, and regular monitoring and grievance redress mechanisms that lead to swift action if foodgrain does not reach the people.

We hope that policymakers and bureaucrats draw lessons from the experiences of these states and see the proposed NFSB as an opportunity to reform the PDS.

\subsection{How would UID help?}

The unique identity (UID) programme will certainly help in eliminating duplicate and fake beneficiaries from the PDS rolls as no resident can have a duplicate number since it is linked to their individual biometrics. The Wadhwa Committee appointed by the Supreme Court ${ }^{1}$ recently corroborated the problem of duplicate cards, noting that the practice of 'multiple ration cards issued under a single name' is widespread nationally. In Delhi alone, Right to Information (RTI) petitions uncovered 901 ration cards issued in the name of one woman. ${ }^{2}$ Even in Tamil Nadu, the problem of ghost ration cards exists, enabling shopkeepers to make illegal gains.

The high number of fake cards compels governments to make verification norms for issuing ration cards more stringent. Some State Governments ask the applicants to provide various documents, such as the electoral roll number, a copy of the electricity bill, or the house rent bill to receive a ration card. This tends to penalise poor and homeless families, and prevents large numbers of BPL families from accessing rations because they lack the necessary documents. Once UID has been extended to the entire population (which may of course take several years), it will be easier to monitor full coverage of cards to each individual in a situation of universal coverage through PDS.

However, in most states (Tamil Nadu is an exception), PDS is not universal but is targeted to the BPL households. They have to be identified according to certain criteria, and the UID would be of little help in such an exercise. Thus the problem of errors of exclusion and inclusion would still remain, though no individual, however rich and powerful he may be, would be able to obtain more than one card. On paper the rich are to be excluded from the list of those eligible for PDS, but in practice UID would not be able to prevent them benefiting from schemes meant for the poor.

Another advantage with the UID is making PDS entitlements portable, as beneficiaries would be able to withdraw their entitlements from any ration shop in the state, if their UID card allows them to do so. This would, however, require linking future Fair Price Shop allocations to the shopkeeper to authenticated offtake by beneficiaries, thus discouraging open market leakages by the shopkeeper and ensuring that only genuine offtake by consumers is permitted. 


\subsection{Provide cash subsidy?}

Large-scale substitution of PDS by direct cash transfers (DCT) is not feasible, as about 60 million tonnes of foodgrains, purchased from farmers annually by providing them a minimum support price, need an outlet for distribution. Besides, DCT needs a good banking structure, a functional registration system, and widespread use of debit cards. At best, it could be tried on a pilot basis in a few poor areas of metropolitan cities.

\section{Malnutrition and underweight children}

Less well understood than hunger is the nagging problem of undernutrition amongst children that leads to them being below normal height and weight for their age. According to the 2011 HUNGaMA report, 42 per cent of children under five are underweight and 59 per cent are stunted in the 100 districts studied across six states. Of the children suffering from stunting, about half are severely stunted (those whose height is less than 3 Standard Deviations from normal for their age group), and of those underweight, about 40 per cent are severely malnourished (those who weigh less than 3 Standard

Deviations from normal for their age group). What is worse is the fact that India has made little progress in reducing malnutrition in the last ten years (Haddad 2009).

Child malnutrition starts very early in life, and it is often an intergenerational issue. Adolescent girls who are themselves underweight give birth to low-weight babies. The child-rearing practices in India unfortunately are highly unscientific, as giving colostrum to the newborn, exclusive breastfeeding for first six months of a child's life, and complementary feeding several times a day after six months are not commonly practised. In the 100 districts studied in the HUNGaMA report, 51 per cent of mothers did not give colostrum to the newborn soon after birth and 58 per cent of mothers fed water to their infants before six months. Besides, due to poor-quality water and lack of toilets, children are exposed to stomach infections, develop diarrhoea, and start losing weight. Also, the mothers have to work long hours away from home without any support system, and are unable to afford health care.

A recent comprehensive evaluation of ICDS (Planning Commission 2011) has concluded that despite the fact that outlay for the ICDS was increased from Rs 121 billion in the X Plan
(2002-07) to Rs 444 billion in the XI Plan

(2007-12), the outcomes were most disappointing.

Only 19 per cent of the mothers reported that the Anganwadi Centre 3 (AWC) provides nutrition counselling to parents. More than 40 per cent of the funds meant for supplementary nutrition (SN) are siphoned off; for financial year 2008/09 the amount of $\mathrm{SN}$ allocation diverted is estimated at Rs 29 billion. Although 81 per cent of children below six years of age were living in an area covered by the AWCs, only 31 per cent children received SN and only 12 per cent received it regularly (Planning Commission 2012). Only 38 per cent of pregnant women and lactating mothers, and 10 per cent of adolescent girls received $\mathrm{SN}$.

However, the commonly held assumption is that food insecurity is the primary or even sole cause of malnutrition. Consequently, the existing response to malnutrition in India has been skewed towards food-based interventions and has placed little emphasis on schemes addressing the other determinants of malnutrition. This is why the government's main intervention, the ICDS programme, has not yet succeeded in making a significant dent in reducing child malnutrition, as the programme has placed priority on food supplementation rather than on nutrition and health education interventions, and targets children mostly older than three, when malnutrition has already set in. Very little of the ICDS resources, in terms of funds and staff time, are spent on children under three years of age (Planning Commission 2012), and this low priority must be reversed. In addition, the focus should be on those ICDS components that directly address the most important causes of undernutrition in India, specifically improving mothers' feeding and caring behaviour, improving household water and sanitation, strengthening referrals to the health system and providing micronutrients.

The basic nature of the programme should be changed from centre-based to outreach-based, as the child under three cannot walk to the centre and has to be reached at his/her home. Another advantage of visiting homes is that the entire family, not just the mothers, are sensitised and counselled.

\section{Some recent policy initiatives}

After the third National Family Health Survey (NFHS-3) came up in 2007 with the startling 
findings that there had been almost no decline in the percentage of underweight children in India between 1998 and 2006, the Prime Minister decided to establish a high-powered Nutrition Council headed by himself. Unfortunately, it met only once, in November 2010, and decided to further strengthen the programme in 200 selected high-burden districts, but formal orders are still to be issued.

The National Food Security Bill recently introduced in Parliament provides that every pregnant woman and lactating mother shall be entitled to one free meal a day during pregnancy and for six months after childbirth, and maternity benefit of Rs 1,000 per month for a period of six months. However, the focus is still on food, and not on health and care-related interventions.

\section{The non-functional childcare system in urban India}

ICDS runs very poorly in urban slum areas. A study of Tamil Nadu, which is considered to be the best state as regards ICDS, commented,

the urban Anganwadis are in terrible condition. Whether winter or summer, they make the kids sit on a paper-thin durrie and even if they soil themselves they are made to sit like that for hours. All they get is a meal but no personal touch. Most women here who go out for work leave their children with private care providers. ActionAid, an international NGO working to alleviate poverty, did a study in 2010 on the homeless in Chennai and discovered that 66 per cent of children under five years were not availing of the ICDS facilites. Many were opting for the creche services of private players. The worst affected are those in the unorganised sector construction workers, domestic help, vendors and so on. They take their children along with them and make them work by pulling them away from schools. The lack of daycare has thus long-term effects (Ghosh 2012).

In urban slums, the problem of appallingly low rent allocations (Rs 1,000 for Delhi, for instance) for hiring spaces and non-availability of government buildings needs to be addressed urgently to fill the gap in universalising services for slum populations. In the short term, portakabins/temporary structures can be put up to provide toilets in those slums where due either to legal issues or space constraints, it is not possible to put up permanent structures.

\section{Improve the reporting system}

ICDS also faces substantial operational challenges, such as lack of accountability due to lack of oversight and an irresponsible reporting system. It appears that State Governments actively encourage reporting of inflated figures from the districts, which renders monitoring ineffective and accountability meaningless. Objective evaluation by NFHS-3 shows that 40.4 per cent of children are underweight, 15.8 per cent of whom are severely malnourished. However, the State Governments report 13 per cent of children as underweight, and only 0.4 per cent as severely malnourished (IAMR 2011: 140). One district Collector, when confronted with such bogus figures, told me that reporting correct data is 'a high-risk and lowreward activity'! The Prime Minister may term the government's performance a 'national shame', but he has not been able to persuade the states to accept that the problem exists!

A recent evaluation of ICDS in Gorakhpur by the National Human Rights Commission ${ }^{4}$ showed that despite Supreme Court orders to provide hot cooked meals, all centres supplied only packaged ready-to-eat food, containing only 100 calories, as against a norm of 500 calories, and 63 per cent of food and funds were misappropriated. The food being unpalatable, half of it ends up as cattle feed. However, such reports, though few, are never discussed in state Assemblies, as they meet now for fewer than 30 days a year. We need a new law making it compulsory for Parliament and Assemblies to meet for at least 150 days a year.

\section{Improve mobility}

The supervisory officials in ICDS do not visit villages, using the excuse that they have no access to a government vehicle. State Governments should provide interest-free loans to CDPOs (Child Development Project Officers) and Supervisors to buy motorbikes, provided they possess a driving licence. State Governments should provide driving training for women staff. Consideration should also be given to holding an annual competition at the district police training centre where the best women workers could be given attractive prizes for their riding skills. As a practical and long-term solution, government 
Box 2 The AWC in Lisubari Village in district Jorhat, ASSAM - A success story

The location of AWCs and self-motivation of AWWs are the two major factors to highlight for good functioning of the AWC. The Lisubari colony AWC is located at a distance of $10 \mathrm{~km}$ from Jorhat town. The AWC is located on the campus of the primary and middle school, in its own building with an attached toilet and store. It has a huge campus with a boundary wall that is shared with the primary and middle school for outdoor activities. The Supervisor also resides nearby, only $0.5 \mathrm{~km}$ from the AWC.

The AWW's own son aged five years also attends preschool activities in the AWC so the AWW is more active for both preschool activities and providing regular food. Moreover, the community, especially mothers and adolescent girls, help the AWW in cooking and other activities at the AWC. The AWW gets help from the community as she is also a member of Mahila Mandal in the village. The Village Management Committee (VMC) has been formed to monitor the activities of the AWC.

For AWC, the AWC gets a cheque in the name of the VMC and the AWW is the secretary of the VMC. The secretary and president purchase the food items for 15 days at a time from the shops recommended by the Supervisor or CDPO. Food has been provided regularly, according to the beneficiaries in the village, despite not having a permanent kitchen.

Source Planning Commission (2011).

should encourage training for girls in upper primary schools in how to ride bicycles, and high school girls in how to ride motorbikes, as part of the syllabus. This will not only improve their mobility and usefulness to their parents, but also give them more self-confidence. The sight of a woman riding a motorbike will also inspire and empower all female adolescents.

The involvement of women, particularly of those from the marginalised communities, has a multiplier impact on outcomes. Women should also be better represented among Supervisors, CDPOs and other ICDS staff above the Anganwadi level. In Rajasthan, most CDPOs are men on secondment from other services, which reduces their sense of ownership within the ICDS. Many backward states, such as UP, Bihar and Jharkhand, have only women as Supervisors and CDPOs. However, there are massive vacancies due to which their effectiveness is limited. In Bihar, for instance, 90 per cent of the Supervisor posts are vacant. Only 64 per cent of Anganwadi workers (AWWs) received their salary either regularly or with a delay of one month, the rest reported delays of two to six months in getting their meagre salaries (Planning Commission 2011).

ICDS should learn from the success of the midday meals programme that runs fairly well even in states not known for efficiency, whereas the supply of packaged food in ICDS even in efficient states is not popular with the children, besides being irregular and discouraging local participation. For children below the age of three years, nutritious and carefully designed locally prepared take-home rations based on locally procured food should be the recommended option, but there could be centre-specific variations. If fortified milk powder is to be provided, it must be manufactured by a wellknown manufacturer. Before inviting financial bids, states must invite technical bids in a transparent manner so that unscrupulous elements involved in the racket of supplying packaged food through bribes are eliminated. Children can eat only small quantities of food and therefore need fat-rich food to obtain the necessary calories. In the absence of oil supplies, there is almost no fat content in the food being given but, for children below three, almost 40 per cent of their calorie requirement should come from fats. This aspect is totally overlooked in the current supplementary nutrition programme (SNP).

Last, India requires a significant increase of targeted investments in health programmes, clinics, disease control, irrigation, potable water, sanitation, and other basic investments, especially in rural India, where the current 
budgetary allocations are inadequate. Higher public investments in these areas need to be accompanied by systemic reforms that will overhaul the present system of service delivery, including issues of control and oversight. Outlays should not be considered as an end in

\section{Notes}

1 See www.im4change.org/news-alert/justicewadhwa-committee-slams-the-pds-1759.html, and www.righttofoodindia.org/pds/ pds_justice_wadhwa_committee_report.html.

2 See http://uidai.gov.in/UID_PDF/Working_ Papers/Circulated_Aadhaar_PDS_Note.pdf.

\section{References}

Ghosh, Padmaparna (2012) 'A Sitter of a Job in Shanty Town', The Times of India, 11 February, www.timescrest.com/society/a-sitter-of-a-jobin-shanty-town-7238 (accessed 8 April 2012)

Haddad, L. (2009) 'Lifting the Gurse: Overcoming Persistent Undernutrition in India', IDS Bulletin 40.4: 1-8

Hirway, Indira (2011) 'NREGA and Gender Empowerment: Understanding the Linkages', draft report submitted to UN Women, New Delhi

HUNGaMA (2011) The HUNGaMA (Hunger and Malnutrition) Survey Report 2011, www.theaahm.org/resources/documents/en/ (accessed 8 April 2012)

IAMR (Institute of Applied Manpower Research) (2011) India Human Development Report 2011, New Delhi: Planning Commission

IFPRI (2011) Global Hunger Index Report: The Challenge of Hunger, Bonn: International Food Policy Research Institute

Indian Express (2011) 'NREGA: Jairam Rejects Pawar Claim, Says No Impact on Farms', themselves. Delivery of food-based schemes requires greater financial resources, but more importantly the quality of public expenditures in these areas. This in turn requires improving the governance, productivity and accountability of government machinery.

3 There are about 1.3 million such centres in India, generally structures of one or two rooms, where children gather for about four hours every morning for various ICDS activities.

4 See http://nhrc.nic.in/Reports/misc/SKTiwari _Gorakhpur.pdf.

22 December, www.indianexpress.com/news/ nrega-jairam-rejects-pawar-claim-says-no-i/ 890514/ (accessed 12 April 2012)

Khera, Reetika (2011) 'Revival of the Public Distribution System: Evidence and Explanations', Economic and Political Weekly 46.44-45

Planning Commission (2012) Report of the Working Group on Nutrition for the 12th Five Year Plan (2012-17), New Delhi: Planning Commission

Planning Commission (2011) Evaluation of the ICDS, New Delhi: Planning Commission, http://planningcommission.nic.in/reports/ peoreport/peo/peo_icds_voll.pdf (accessed 8 April 2012)

Planning Commission (2004) Evaluation of the Public Distribution System, New Delhi: Planning Commission

Puri, Raghav (2012) 'Reforming the Public Distribution System: Lessons from Chhattisgarh', Economic and Political Weekly, 4 February 